audible range. At the greatest amplitude of modula. tion, the change in carrier frequency is termed the deviation, and the value of this as used for broadcasting in the United States and likely to be adopted in Britain is $\pm 75 \mathrm{kc} . / \mathrm{s}$. In contrast with this system is that of amplitude-modulation, which is used in normal broadcasting, and in which the amplitude of the carrier is varied at the modulation frequency from zero to twice its normal unmodulated value, the frequency of the carrier wave remaining unaltered during the modulation process. Any increase of modulation amplitude beyond the above maximum value would result in distortion both at the transmitter and at the receiver. In the case of frequency modulation, there is no precisely defined point at which distortion sets in, so that if the transmitter and receiver circuits are suitably designed, a greater range of modulation can be achieved with the frequency- than with the amplitude-modulation system.

In order to render a frequency-modulated signal audible, the receiver uses a device known as a 'discriminator', which in effect converts it into an amplitude-modulated signal, which may then be detected by any of the usual methods. Since no change in amplitude of the carrier wave is required to convey intelligence, the transmitter can be operated under constant load conditions of high efficiency; and at the receiver a limiting device can be used to make it insensitive to amplitude changes, and thus limit the effects of receiver noise and electrical interference. While it would not be worth while using frequency-modulation on medium or long waves, because the band-width would have to be restricted, this does not apply to ultra-short waves, less than 10 metres in length; and the wide-band modulation can here be used to advantage with an extended audio-frequency range and improved quality of reception.

These advantages of the frequency-modulation system for broadcasting on ultra-short waves are discussed in some detail in the article referred to above, and illustrated by tabulated results and graphs applicable to frequencies of $45 \mathrm{Mc} . / \mathrm{s} .(6 \cdot 7 \mathrm{~m}$.) and $90 \mathrm{Mc} . / \mathrm{s}$. $(3 \cdot 3 \mathrm{~m}$.$) . For example, the electrical$ interference from motor-car ignition systems, which is a serious factor in the reception of ultra-short wave broadcasting, is much less serious with frequency. than with amplitude-modulation. Incidentally, in the course of experimental observations on this point made alongside a main arterial road, it was found to be extremely rare to get any interference from military vehicles, which have suitable radio-frequency suppressors fitted. The universal fitting of suppressors to motor vehicles would therefore increase the service area of a broadcasting transmitter very considerably. While the interference tests which have so far been made indicate that, on a frequency of $90 \mathrm{Mc} / \mathrm{s}$., the field-strength required to give satisfactory reception in the presence of a given amount of interference is only about one-third that required on $45 \mathrm{Mc}$. $/ \mathrm{s}$., it is to be noted that the field-strength obtained on the higher frequency may be less, due to greater attenuation and screening effects. The effective range is thus about the same on the two frequencies, and in both cases the use of horizontal polarization appears to be preferable.

The propagation of ultra-short waves is not greatly affected by the nature of the ground over which the waves pass, as is the case for medium and long waves ; but the shorter waves are more affected by ground contour, hills casting shadows and thereby degrading the reception conditions in valleys. Considerable advantage is obtained by placing the transmitter on high ground, with as high an aerial as possible. The meteorological conditions in the atmosphere also affect the propagation of ultra-short waves, causing them to be refracted and so to reach greater distances than would otherwise be the case. The B.B.C. has carried out surveys of field-strength on both 45 and $90 \mathrm{Mc}$./s. from transmitters located at the Alexandra Palace Television Station and at its Research Department, near Oxford. Typical results described and illustrated in the paper show the effect of ground contour and the fading that is encountered when the receiving point is at or beyond direct optical range from the transmitter.

The latter portion of Mr. Kirke's article is concerned with the planning of an ultra-short wave broadcasting service, and tables are given showing the coverage area to be expected on each of the two frequencies considered, and for four grades of service between first-class reception in an urban area to second-class reception in quiet rural surroundings. Confirmation of these calculations is being obtained by the provision of practical data on the reception of frequency-modulation in the home, in the course of special tests in which members of the staff of the B.B.C. co-operate. It will thus be realized that active consideration is being given to the possibilities of ultra-short wave broadcasting with the view of relieving the present congestion in the medium and long-wave bands, and providing a satisfactory frequency-modulation service of high quality throughout Great Britain.

\section{SCIENTIFIC CENTENARIES IN 1947}

\author{
By Engineer-Captain EDGAR C. SMITH, \\ O.B.E., R.N.
}

A REVIEW of the centenaries which occur in 1947 may well begin with a footnote to Prof. W. M. Smart's address to the Royal Astronomical Society on "John Couch Adams and the Discovery of Neptune", published in Nature of November 9 1946. With the publication of the facts connected with the discovery, the controversy began to subside, and at the Oxford meeting of the British Association in June 1847, Adams and Le Verrier met. The latter had been invited to England by Airy; and J. D. Forbes recorded how he dined at Prof. Powell's with a small but excellent party including Airy, Le Verrier and Adams. Afterwards Forbes went to the Observatory to see Neptune. "Fancy the interest," he wrote, "of seeing the new planet for the first time in company with its two discoverers! Of course, there could be no going to bed without seeing it, and accordingly as it rose late, I did not get back to my college till very nearly two in the morning." A month later Le Verrier was at Cambridge, and so was Otto Struve, and Murchison wrote, "Whilst walking across the quadrangle of Trinity, Leverrier on one arm and Struve on the other, we saw the Duke of Wellington coming towards us in his red gown and I at once said to the two great astronomers, 'Now, gentlemen, here is the opportunity'. Struve was overjoyed, saying it was the thing of all others he wished; but Leverrier turned on his heel and left us saying, 'Pardonnez, c'est plus fort que moi ; jo suis Francais'." 
That Oxford meeting was memorable for another reason, for it marked the beginning of the friendship of Joule and Prof. William Thomson, afterwards Lord Kelvin. To the Physics Section, Joule gave an account of his experiments on the mechanical equivalent of heat. His previous communications had not excited much interest, and this time the same thing might have happened had not "a young man ... risen in the Section and by his intelligent observations created a lively interest in the new theory". The young man was Thomson, then twentythree years old ; Joule was twenty-seven. In a letter to Bottomley, Thomson said "that at first he thought Joule must be wrong but as he listened he recognised that Joule had certainly a great truth and a great discovery and a most important measurement to bring forward"; about a fortnight later Joule and Thomson met in Switzerland, where Joule was spending his honeymoon.

Of the notable men of science born a century ago, there is no need to say much of Thomas Alva Edison, man of a thousand patents, who was born in Milan, Ohio, on February 11, 1847, and died at West Orange, New Jersey, on October 18, 1931 ; or of Alexander Graham Bell, who was born in Edinburgh on March 3, 1847, and died near Baddeck, Nova Scotia, on August 2, 1922. To them both could be applied the oft-quoted epitaph to Wren to be seen in the north transept of St. Paul's Cathedral. Bell's father, uncle, brothers and grandfather had taught the laws of speech in the Universities of Edinburgh, Dublin and London, and his own work was directly. in line with theirs. Edison's forbears-colonists, farmers, merchants, men of exceptional physique, energetic and independent-had nothing to do with science, and in the boy's environment there was little to suggest that he would sit up all night poring over Faraday's writings, or become known as "the Wizard of Menlo Park".

In Edison's early days, telegraphy was the principal branch of electrical engineering, and it attracted many scientifically trained investigators. Among these was William Edward Ayrton, F.R.S. (18471908), inventor with John Perry of many electrical instruments and a promoter of technical education. $\mathrm{He}$ was president of the Institution of Electrical Engineers and of the Physical Society, and several times dean of the Central Technical College, London. The Russian electrician, Paul Jablochkoff (1847-94), was a telegraphist, and at the age of twenty-four was director of the telegraph between Moscow and Kursk. This post he gave up to work at electric lighting problems. His electric 'candles', patented in 1876, were shown in the East India Docks, London, in the following year, and in 1878 were used for lighting the Place de l'Opéra, Paris. Prof. Silliman of Yale was delighted with them, and wrote, "The effect is magnificent and at this moment there exists nothing in this city of splendid effects to compare with the magical scene. The vista is about twothirds of a mile and the effect incomparably finer than any show of artificial illumination ever before seen." Alas ! Jablochkoff's 'candles' had to give way to the lamps of Swan and Edison, and their inventor returned to Russia and apparently died in poverty. Electrical engineering was also furthered by the work of the distinguished engineer and educationist, Sir Alexander Blackie William Kennedy, F.R.S. (1847-1928). Kennedy started work in a Thamesside marine engineering shop; but at the age of twenty-seven was made professor of engineering in
University College, London, where he founded the first laboratory for experimental work on an engineering scale. For twenty-five years he held his chair, and then he turned from civil and mechanical engineering to electrical engineering. His services were sought for many schemes, and he was president of both the Institution of Civil Engineers and the Institution of Mechanical Engineers-which body will in June fittingly commemorate the centenary of its foundation at Birmingham with George Stephenson as its first president.

At University College, Kennedy counted among his fellow professors another great London teacher, Sir Edwin Ray Lankester, F.R.S. (1847-1929), who held the chair of zoology from 1874 until 1890, and some time afterwards became director of the British Museum (Natural History). He was the son of Dr. Edwin Lankester, F.R.S. (1814-74), a physician, coroner and botanist, who at the time of his son's birth was secretary of the Ray Society, founded in 1844.

To these names of distinguished men whose cen. tenaries fall this year may be added those of Thomas Andrews, F.R.S. (1847-1907), a Sheffield iron-master and an active investigator into the structure and properties of metals ; William Denny (1847-87), of Dumbarton, the first private ship-builder to set up an experimental tank after the plans of his friend, William Froude; and James Ludovic Lindsay, twenty-sixth Earl of Crawford and ninth Earl of Balcarres (1847-1913), to whose munificent gift of astronomical instruments and books was mainly due the building of the fine Royal Observatory on Black. ford Hill, Edinburgh.

The losses by death among men of seience in 1847 do not appear to have been as numerous as they were in 1846, but geology and mineralogy were all the poorer by the passing of Alexandre Brongniart (1770-1847), long the associate of Cuvier. Brongniart was director of the porcelain factory at Sèvres and professor of mineralogy in the Museum of Natural History, Paris. With Cuvier he made many geological excursions into the country around Paris; after reviewing their joint labours, Geikie said that by their demonstration of the use of fossils for the determination of geologieal chronology, they deserve an honoured place among the founders of geology. Six months before Brongniart died, Mary Anning died, at the age of forty-seven. She was the daughter of a carpenter and vendor of natural curiosities of Lyme Regis ; when a girl of only twelve, she found the fossil bones of an ichthyosaurus, and when twenty-one and twenty-seven respectively, discovered the first specimens in England of a plesiosaurus and a pterodactyl. She died on March 9, 1847, and fifteen years later the Geological Society erected a memorial window to her in the parish church of Lyme Regis. James M'Cullagh was the son of a small farmer, but he too made a name for himself. By intense application of his unusual powers, he rose to be professor of natural philosophy in Dublin and secretary of the Royal Irish Academy, his writings on the theory of light gaining for him in 1842 the Copley Medal of the Royal Society. Overwrought, he died by his own hand on October 24, 1847, at the age of thirty-eight. Last in this group is David Mushet (1772-1847), who died at the age of seventy-four. $\mathrm{He}$ is perhaps best remembered for his important discovery of the Black Band Iron. stone through which many fortunes were made; but he did notable work in other directions, one authority 
writing that "He found the knowledge of iron, and of the ores from which the metal is derived, wrapped in the darkness of barbarism; he evolved and brought to light the true principles of both by a series of experiments, in which the most patient investigation and untiring bodily labour were oombined".

At a time when so much thought is being devoted to technical education, it is worth recalling that the earliest modern technical colleges were those founded by the French Government in the eighteenth century. One of these was the Ecole des Ponts et Chaussées, inaugurated just two hundred years ago by the administrator, Daniel Charles Trudaine, with the famous engineer, Jean Rodolphe Perronet (1708-94), "the Telford of France", as its director. The Corps des Ponts et Chaussées had been organised in 1716 for the maintenance of the roads, bridges, canals and harbours of France; and the School was for preparing likely candidates for the Corps. "The Corps and the School," said Mr. S. B. Hamilton, "closely associated, formed a professional body of men specializing in civil engineering, as distinct from military engineering, and from architecture. From this period, therefore, we may regard the separation of the three professions as having become effective." The School had many students who distinguished themselves, and one of these was Jacques-Elie Lamblardie (1747-97), who succeeded Perronet as director and held that position at the time of the Revolution, when for a time the School was merged in the Ecale Centrale des Travaux Publies. He had previously done good work on the rivers and harbours of Normandy, erected a bascule bridge at Le Havre, and commenced a series of large-scale tests on timber, which were after his death continued by his colleagues.

Of never-ending interest is the period which saw the work of Huygens, Newton, Boyle, Leibniz and Hooke, and the founding of the Royal Society and the Academies of Sciences in Paris, Berlin and elsewhere. All these men and institutions are recalled by the lives of Denis Papin and Marten Triewald. Papin was born three hundred years ago, and Triewald died two hundred years ago. At various times the assistant of Boyle, Huygens and Hooke, correspondent of Leibniz, curator of the Royal Society and the first to show how to construct an atmospheric machine having cylinder and piston, Papin once wrote to Leibniz in 1696: "The number of machines and new inventions which I have in my head becomes ever greater, and I have no stronger desire than to live to see their effect, which they will produce as soon as they can be properly constructed". One of the things Papin sought to do, Thomas Newcomen achieved, and part of Triewald's fame is due to the construction by him of the first Newcomen atmospheric pumping engine seen in the Swedish mines. His stay of ten years in England had made him known to Newton and Desaguliers, and back in his own country he lectured here and there on experimental science. He also made a collection of instruments still preserved in the University of Lund. An active, energetic and versatile man, he was one of the six founders of the Royal Swedish Academy of Science. A translation of his "Short Description of the Atmospheric Engine" (1734) was published by the Newcomen Society in 1928. Papin was born at Blois, France, on August 22, 1647, and died some time after 1712. Triewald was born in Stockholm, being baptized on November 21, 1691 ; he died on August 8, 1747. Papin is also remembered for his invention of the digester known by his name. It is recorded by Evelyn that Papin cooked a meal for some fellows of the Royal Society in his digester : "This philosophical supper caused much mirth amongst us and exceedingly pleased all the company".

In 1908 the tercentenary of the birth of Evangelista Torricelli was celebrated at Faenza. Later on, under the auspices of the municipality of that town, his collected works were published in three volumes; a review of them appeared in Nature of January 29, 1920. This year marks the tercentenary of his death, and also of that of his countryman, Bonaventura Cavalieri, who was born ten years before Torricelli. One has an assured place in the history of science for his discovery of the pressure of the atmosphere and his invention of the barometer; while the other is remembered among mathematicians for his method of indivisibles. The two men were friends of Galileo, through whom Cavalieri was appointed to the chair of mathematics in the University of Bologna. In France, the year 1647 saw the death of Claude Mydorge, an associate of Descartes and Fermat, and a member of the small society from which sprang the French Academy; while in Copenhagen on October 8, 1647, the death occurred of Christian Longomontanus, who worked during 1589-98 with Tycho Brahe at Uraniborg, and from 1605 until his death held the chair of mathematics at Copenhagen.

Finally, looking back yet another century, in 1547 Johann Schoner, the contemporary of Copernicus, died at the age of seventy. For many years he was a professor of mathematics in Nuremberg, and wrote on the globes, geography, dialling and astronomy. It was to him that the enthusiastic Rheticus wrote after visiting Copernicus: "Believe me, most learned Schonerus, that this man, my instructor, in all kinds of learning, and in the science of astronomy, is not inferior to Regiomontanus. I freely compare him to Ptolemy; not that I think Regiomontanus less than Ptolemy, but because my preceptor has a felicity in common with Ptolemy, that, by the Divine Assistance, he would finish the Reformation of Astronomy ; whereas Regiomontanus, $\mathrm{O}$ cruel fate! died before he had erected his pillars".

\section{OBITUARIES}

\section{Dr. Hugo Obermaier}

WITH the death of Hugo Obermaier, which has recently taken place at Fribourg in Switzerland, prehistorians have lost a pioneer colleague of international reputation, the author of at least two widely known books and numerous important articles which have appeared in learned journals; his friends a figure beloved for the unselfish dignity and fidelity of his nature ; and the Continent of Europe one of those, alas, now all too rare learned men to whom frontiers are unimportant. He was a good European -if a saddened one.

Born in 1877, the son of the civic librarian of Ratisbon in Bavaria, he studied in Vienna under Hoernes and others, and early developed a flair for prehistory, working at pleistocene geology with the famous Albrecht Penck. In 1904 he went to Paris, and there first met his life-long friend, the Abbé Breuil. The latter has told me the following anecdote of Obermaier at this time which is characteristic of his fine personality. It appears that he was hoping 